\title{
Structure and operation strategies of an automatic supervisory control system for the KEPCO UPFC
}

\author{
Seon-Ju Ahn · Dong-Woo Lee · Seung-II Moon
}

Published online: 9 August 2008

(C) Springer-Verlag 2008

\section{Erratum to: Electr Eng}

\section{DOI 10.1007/s00202-008-0100-z}

The original version of this article unfortunately contained a mistake. The presentation of Fig. 5 was incorrect.

The correct figure is given below.

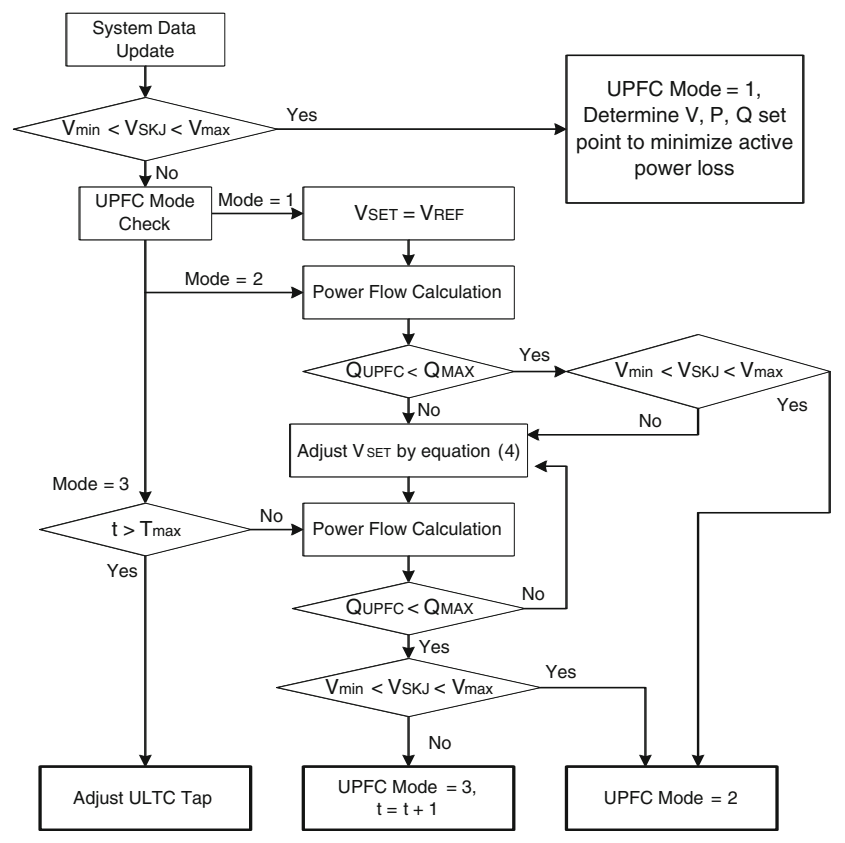

Fig. 5 Flowchart of the operation algorithm in the normal state

The online version of the original article can be found under doi:10.1007/s00202-008-0100-z.

S.-J. Ahn $(\varangle) \cdot$ D.-W. Lee · S.-I. Moon Seoul National University, Seoul, South Korea

e-mail: lion52@powerlab.snu.ac.kr 